\title{
Damage of Rock Mass by Double-Hole Blasting with Slit Charge and Development of Stress Wave under High In Situ Stress
}

\author{
Jianyu Zhang $\mathbb{D}^{1,2}$ Zegong Liu $\mathbb{D}^{1,{ }^{1,2}}$ Shigui Fu $\mathbb{D}^{1},{ }^{1}$ and Guodong Qiao $\mathbb{D}^{1}$ \\ ${ }^{1}$ Anhui University of Science and Technology, School of Safety and Engineering, Huainan 232001, Anhui, China \\ ${ }^{2}$ Key Laboratory of Mine Safety and High Efficient Mining Jointly Built by Province and Education Ministry, \\ Anhui University of Science and Technology, Huainan 232001, China
}

Correspondence should be addressed to Zegong Liu; zgliu@aust.edu.cn

Received 26 October 2021; Revised 21 December 2021; Accepted 30 December 2021; Published 24 January 2022

Academic Editor: Hamid Toopchi-Nezhad

Copyright (c) 2022 Jianyu Zhang et al. This is an open access article distributed under the Creative Commons Attribution License, which permits unrestricted use, distribution, and reproduction in any medium, provided the original work is properly cited.

\begin{abstract}
To study the influence of high ground stress on crack propagation and stress propagation during deep rock blasting, a theoretical model of blasting stress wave propagation and rock damage under in situ stress conditions is developed. The implicit-display coupling method of ANSYS/LS-DYNA is used to numerically simulate the double-hole blasting of the slit charge under two-way equal pressure and two-way different pressures. A theoretical analysis shows that, in blasting under ground stress conditions, at the near end of the blasting source, the loading stress does not increase sufficiently upon unloading, and the stress wave peak value decreases with the increase in ground stress, while the opposite behavior is obtained at the far end of the blasting source. Under the two-way isostatic condition, the crack that develops at $45^{\circ}$ deviates from the principal stress direction. Under the condition of twoway different pressures, the crack develops in the direction of $\theta\left(\theta=\arctan \left(\sigma_{x} / \sigma_{y}\right)\right)$ with the principal stress angle. The numerical results under the two-way equal pressure conditions show that a higher ground stress leads to a larger suppression of the blasting effect. When the ground stress is smaller, the slit charge cannot be effectively suppressed, and the cracks are biased toward the cutting direction. The numerical results under two-way different pressures show that the in situ stress has a significant inhibitory effect on the vertical cracks and that the cracks are more likely to develop in the direction of high stress after blasting. These results provide a reference for directional blasting of deep rock masses.
\end{abstract}

\section{Introduction}

The rapid economic and social development has led to a large consumption of mineral resources. With the gradual depletion of mineral resources in the shallow part of the Earth, mining of deep mineral resources has become normal. With respect to coal mines, the China's coal resources with depths larger than $1,000 \mathrm{~m}$ accounted for $53 \%$ of the total proven coal resources [1]. The mining depth continues to increase at a rate of $8-12 \mathrm{~m}$ per year [2]. In contrast to shallow mineral resources, deep resource mining faces numerous severe challenges, such as complex stress conditions [3]. Rock drilling and blasting rock is still the main method of deep hard rock excavation [4]. The deep rock blasting is the result of the combined effect of blasting stress waves and ground stress [5].
To study the influence of in situ stress on the rock mass blasting, numerous studies focused on two aspects: rock breaking mechanisms (including the crack propagation law) and engineering applications. Regarding the rock breaking mechanism and crack propagation law, Yang et al. reported that when the rock mass is blasted under the initial stress conditions, the ground stress at the blasting boundary will be released suddenly, causing a damage area increase [6]. Xiao et al. showed that the action of the unloaded radial tensile stress causes accumulated strain energy release in the radial direction (in the elastic zone) when blasting is carried out under a high ground stress. Therefore, a new damage is formed in the elastic zone [7]. Yi et al. reported that, in the early stage of rock blasting, the expansion of blasting lines was mainly affected by the dynamic stress generated by the explosion. However, the blasting stress wave decayed rapidly 
near the blast crack. Finally, cracks were generated by the original ground stress [8]. Ge showed that the expansion length of the burst pattern decreases with the increase in the ground stress level and that the burst pattern mainly expands in the direction of the maximum principal stress [9]. Yang et al. reported that the ground stress reduced the hoop stress after blasting. This process reduces the action time of the hoop stress and inhibits crack development [10]. Li et al. reported that a large amount of elastic energy with a high ground stress is stored in the rock mass, and thus it will have a significant superposition effect with the energy after blasting [11]. Regarding the engineering application, Xie et al. proposed an improved blasting method suitable for deep rock masses [12]. Liu et al. optimized the evaluation index of flaw detection using blasting sound waves under a high ground stress [13]. Fan et al. established a vibration peak prediction model based on the principle of energy balance under a high ground stress [14]. The establishment of this model is based on the vibration data monitored during the blasting process of the deep-buried tunnel of the Jinping II Hydropower Station. Zhang et al. defined the correction factor in loading explosives (under in situ stress) and proposed a specific loading design method that considers the field stress [15]. These research results have promoted the research on blasting theory under ground stress to a certain extent. However, in the directional blasting of deep rock and soil, the slitting charge technology, which is gradually and widely used, lacks in-depth discussion. In addition, blasting requires multiple blasting holes to explode simultaneously in actual blasting engineering. Therefore, it is also necessary to consider whether the cracks between the blast holes can communicate with each other. Therefore, further detailed studies on the double-hole blasting technology of the slitting charge under ground stress conditions are required.

This study establishes a stress wave propagation model and rock mass blasting damage model under in situ stress conditions. The stress wave propagation laws in the rock mass blasting loading and unloading processes under ground stress conditions are evaluated. The expansion law of the burst pattern of two-way equal pressure and two-way different pressures is obtained. We used the implicit-display coupling method of ANSYS/LS-DYNA to study the crack propagation and penetration of the slotted charge double-hole blasting under different ground stress conditions. The stress wave state at the near and far ends of the blasting point and the attenuation law of the stress wave were analyzed. The obtained results could guide the directional blasting of deep rock masses.

\section{Mechanism}

2.1. Stress Wave Propagation Model under Ground Stress. The stress wave propagation law after the rock mass is loaded with ground stress can be simplified into a two-dimensional model for illustration. We create a plane with length and width dimensions of $L$ here. A uniformly distributed compressive stress $\sigma_{0}$ is then applied to the left boundary of the plane and a displacement constraint is applied to the right boundary of the plane. Finally, $X$-axis is established in the horizontal direction passing through the center point of the plane. A schematic diagram of the model is shown in Figure 1.

A uniformly distributed plane stress wave is applied to the left boundary of the model, denoted as $F(t)$. We consider a differential unit dy in the vertical direction. The force $F(t)$ in the direction of the differential unit is denoted as $f(t)$. At this time, the stress condition is $\sigma(L, t)=f(t)$ at $x=L$. The stress wave is a gradual loading process when $0<t<t_{1}$. At $t_{1}<t<t_{2}$, the unloading process is gradual. This is the stable stage after unloading when $t_{2}<t$. At $x=L$

$$
f(t)=\left\{\begin{array}{l}
\sigma_{0}, t=0 \\
f_{1}(t), 0(t) t_{1} \\
f_{2}(t), t_{1}(t) t_{2} \\
\sigma_{0}\left(t_{2}\right) t
\end{array}\right.
$$

During the blasting process, plastic deformation occurs during the loading process, while the unloading process is assumed to be elastic

$$
\sigma_{2}=\sigma_{1}+E\left(\varepsilon_{2}-\varepsilon_{1}\right)
$$

where $\sigma_{1}$ is the maximum stress during the loading process, $\varepsilon_{1}$ is the maximum strain during the loading, $\sigma_{2}$ is the stress after the unloading, $\varepsilon_{2}$ is the strain after the unloading, and $E$ is the modulus of elasticity.

The governing equation of the loading process is similar to the governing equation of the elastic wave. The control equation for the unloading process can be expressed as

$$
\frac{\partial^{-2} u_{2}}{\partial t^{2}}=C_{0}^{2} \frac{\partial^{-2} u_{2}}{\partial x^{2}}+\frac{1}{\rho} \frac{\mathrm{d} m}{\mathrm{~d} x}-C_{0}^{2} \frac{\mathrm{d} \varepsilon_{m}}{\mathrm{~d} x} .
$$

The elastic wave velocity is higher than the plastic wave velocity, while the wave velocity during the unloading process is higher than the wave velocity during the loading process. Therefore, the initial propagation velocity formula for the unloading boundary [16]:

$$
C_{2}=\frac{C_{0}^{2}}{C}\left[\sqrt{1+3\left(\frac{C}{C_{0}}\right)^{2}}-1\right]
$$

where $C_{0}$ is the elastic wave velocity and $C$ is the plastic wave velocity.

For rock materials, the plastic wave velocity decreases with the increase in the initial ground stress, whereas the elastic wave velocity is unchanged [17]. Equation shows that the stress wave propagation velocity $C_{2}$ at the unloading boundary decreases with the increase in ground stress, which indicates that the peak value of the stress wave will attenuate more slowly with the increase in ground stress. Thus, there is a critical point. At the critical point close to the blasting source, the loading stress does not increase sufficiently upon unloading, while the peak stress wave decreases with the increase in ground stress. However, when the critical point is far away from the blasting source, the peak value of the stress wave increases with the increase in ground stress. 


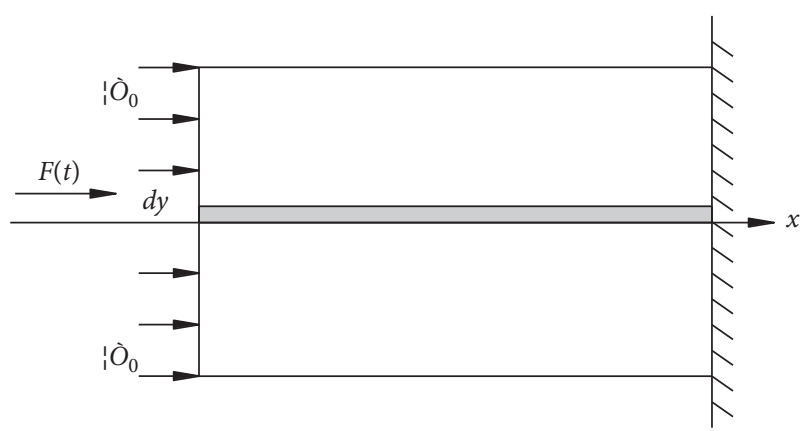

FIGURE 1: Stress wave propagation model under ground stress.

2.2. Law of Crack Propagation under Ground Stress. A blasting damage model of the rock mass under the ground stress state is developed, as shown in Figure 2. The center of the model is a blast hole. A horizontal ground stress $\sigma_{x}$ is applied to the right boundary of the model, a vertical ground stress $\sigma_{y}$ is applied to the upper boundary of the model, and displacement constraints are applied to the left and lower boundaries of the model. During the propagation of the blasting stress wave, a compressive stress $\sigma_{r}$ is generated in the radial direction, while a tensile stress $\sigma_{\theta}$ is generated in the tangential direction. We consider a differential unit on the model, defined by $a$, and perform a force analysis on it:

$$
\left\{\begin{array}{l}
\sigma_{r}-\sigma_{x} \cos \theta-\sigma_{y} \sin \theta \text { (radial stress) } \\
\sigma_{\theta}-\sigma_{x} \frac{\sin \theta}{\sigma_{\theta}}-\sigma_{y} \cos \theta \text { (tangential stress). }
\end{array}\right.
$$

According to the blasting theory, the tensile strength of a rock mass is considerably lower than its compressive strength. The main type of damage due to rock blasting is the formation of circumferential cracks caused by tensile stress [18]. In the middle area of blasting, the blasting stress wave is not sufficient to crush the rock mass [19]. Therefore, only the tangential tensile stress is discussed.

(1) When $\sigma_{x}=\sigma_{y}$,

$$
\left\{\begin{array}{l}
\sigma_{\theta}-\sigma_{y}\left(\theta=0^{\circ}\right), \\
\sigma_{\theta}-\sigma_{x} \sin \theta<\sigma_{\theta}-\sigma_{y} \cos \theta\left(0^{\circ}<\theta<45^{\circ}\right), \\
\sigma_{\theta}-\frac{\sqrt{2}}{2} \sigma_{x}=\sigma_{\theta}-\frac{\sqrt{2}}{2} \sigma_{y}\left(\theta=45^{\circ}\right), \\
\sigma_{\theta}-\sigma_{x} \sin \theta<\sigma_{\theta}-\sigma_{y} \cos \theta\left(45^{\circ}<\theta<90^{\circ}\right), \\
\sigma_{\theta}-\sigma_{x}\left(\theta=90^{\circ}\right) .
\end{array}\right.
$$

At the same distance from the blast hole, the tensile stress in the $45^{\circ}$ diagonal direction is larger than the tensile stress in the horizontal and vertical directions.

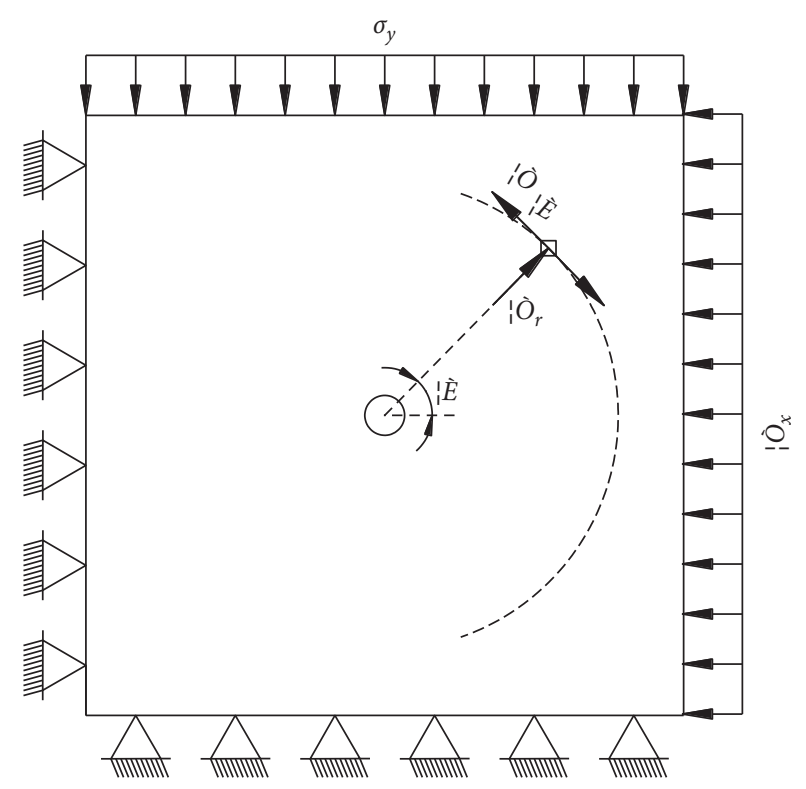

Figure 2: The damage model of rock mass blasting under the ground stress state.

In the $0^{\circ}-45^{\circ}$ and $45^{\circ}-90^{\circ}$ regions, the tensile stress toward the $45^{\circ}$ diagonal is larger than the tensile stress away from the $45^{\circ}$ diagonal. Macroscopically, this shows that radial cracks develop along $45^{\circ}$ away from the principal stress direction and that, closer to the $45^{\circ}$ direction, the cracks are denser. Therefore, tensile cracks are most likely to occur when the forces on the differential element are balanced and the crack length in the $45^{\circ}$ direction is largest. This rule is also applicable in the $135^{\circ}, 225^{\circ}$, and $315^{\circ}$ directions.

(2) When $\sigma_{x} \neq \sigma_{y}$,

$$
\left\{\begin{array}{c}
\sigma_{\theta}-\sigma_{x} \sin \theta \gg \sigma_{\theta}-\sigma_{y} \cos \theta\left(\sigma_{x} \gg \sigma_{y}\right) \\
\sigma_{\theta}-\sigma_{x} \sin \theta \ll \sigma_{\theta}-\sigma_{y} \cos \theta\left(\sigma_{x} \ll \sigma_{y}\right)
\end{array} .\right.
$$

When the tensile stress is balanced, the crack growth is best, and thus

$$
\theta=\arctan \frac{\sigma_{x}}{\sigma_{y}}
$$

When the horizontal ground stress is considerably larger than the vertical ground stress, the crack propagation in the horizontal direction is suppressed and the crack develops in the vertical direction. When the horizontal ground stress is considerably smaller than the vertical ground stress, the crack propagation in the vertical direction is suppressed, and the crack develops in the horizontal direction. When there is a small difference between them, the angle between the crack development direction and principal stress direction is $\theta$. 


\section{Development of a Numerical Model}

In the actual rock blasting process, to achieve the ideal blasting effect, numerous reasonably arranged blast holes are usually used for blasting. If the single-hole blasting model is used, it cannot reflect the mutual influence between the blast holes and is quite different from the actual situation. Therefore, we use the ANSYS/LS-DYNA software to develop a numerical model for the double-hole blasting of the slotted charge under ground stress conditions.

The model developed in this study and schematic of the ground stress application are shown in Figure 3. The model dimensions are $100 \mathrm{~cm} \times 60 \mathrm{~cm}$. The blast holes are located on the horizontal sides of the center point of the model. The blast hole spacing is $40 \mathrm{~cm}$. The blast hole diameter $D_{1}$ is $2 \mathrm{~cm}$. The explosive diameter $D_{2}$ is $1.6 \mathrm{~cm}$. The thickness $d_{1}$ of the slit tube is $0.4 \mathrm{~cm}$ while the slit width $d_{2}$ is $1 \mathrm{~cm}$. A horizontal ground stress $\sigma_{x}$ is applied to the right boundary of the model, a vertical ground stress $\sigma_{y}$ is applied to the upper boundary of the model, and displacement constraints are applied to the left and lower boundaries of the model. To restore the actual situation and eliminate the influence of the reflected stretching wave caused by the boundary size, we impose a nonreflective boundary condition on the surrounding boundary.

3.1. Riedel-Hiermaier-Thoma (RHT) Material Model of Rock Mass. We employ the RHT model for the rock mass developed based on the Holmquist-Johnson-Cook (HJC) model [20]. This model follows the pressure dependence, strain rate sensitivity, and compression damage softening characteristics of the HJC model and introduces tension and compression damage to simulate the dynamic response history of brittle materials such as rocks under explosive loads. The model also introduces three control failure surfaces, failure surface, elastic limit surface, and residual strength surface, which can better describe the evolution law of material failure stress, initial yield stress, and residual stress [21]. The failure stress is related to the hydrostatic pressure $(p)$, rod angle $(\theta)$, and strain rate $(\varepsilon)$ and is expressed as

$$
\sigma_{e q}^{*}(p, \theta, \dot{\varepsilon})=\gamma_{C}(p) R_{3}(\theta) F_{\text {rate }}(\dot{\varepsilon})
$$

where $R_{3}(\theta)$ is the angular even function on the deviated plane, $F_{\text {rate }}(\varepsilon)$ is the strain rate strengthening factor, and $\gamma_{\mathrm{C}}(p)$ is the equivalent stress on the compression meridian,

$$
\gamma_{C}(p)=A\left(p^{*}-p_{\text {spall }}^{*} F_{\text {rate }}(\dot{\varepsilon})\right)^{N},
$$

where $\mathrm{A}$ and $\mathrm{N}$ are failure surface parameters (dimensionless), $P^{*}$ is the normalized hydrostatic pressure (dimensionless), $P_{\text {spall }}^{*}=P_{\text {spall }} / f_{c}$ is the normalized spalling strength (dimensionless), $f_{\mathrm{c}}$ is the uniaxial tensile strength $(\mathrm{Pa})$, and $P_{\text {spall }}$ is the spalling strength $(\mathrm{Pa})$.

In addition, a damage variable $D$ is introduced to describe the residual failure surface. The damage variable $D$ is defined by the accumulation of nonlinear deviatoric strain [22]:

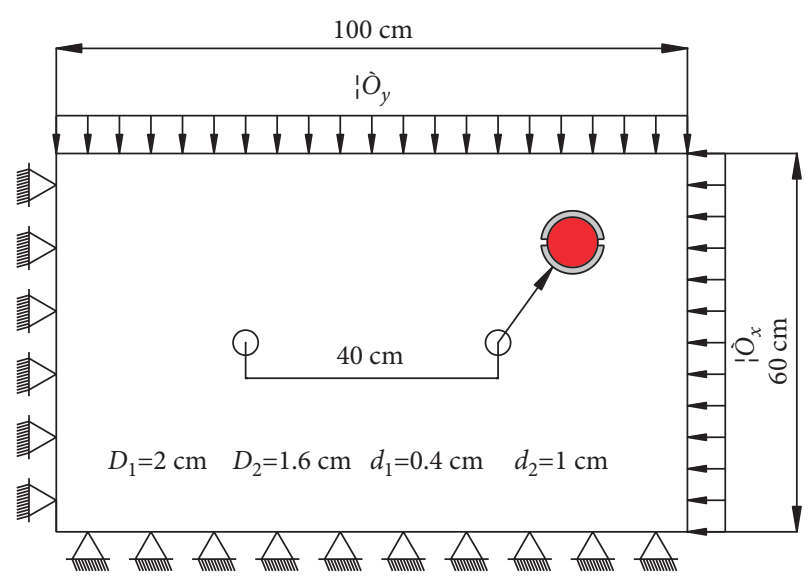

Figure 3: Numerical calculation model.

$$
\begin{aligned}
& D=\sum \frac{\Delta \varepsilon_{P}}{\varepsilon_{f_{\text {min }}},} \\
& D\left(P^{*}-P_{\text {spall }}^{*}\right)^{D_{2}}>\varepsilon_{f_{\text {min }}},
\end{aligned}
$$

where $\varepsilon_{\mathrm{P}}$ is the plastic strain increment (dimensionless), $\varepsilon_{f_{\min }}$ is the minimum plastic strain when the material fails (dimensionless), and $D_{1}$ and $D_{2}$ are damage constants (dimensionless). The rock mass RHT model parameters are obtained from the AUTODYN material library [23] (see Table 1 for details).

3.2. Explosive Materials and State Equation. We use *MAT_HIGH_EXPLOSIVE_BURN to simulate explosive materials and Jones-Wilkins-Lee (JWL) equation of state to describe the external work of explosion and driving process of detonation product expansion [24]. The JWL state equation is

$$
P=A\left(1-\frac{\omega}{R_{1} V}\right) e^{-R_{1} V}+B\left(1-\frac{\omega}{R_{2} V}\right)+\frac{\omega E_{0}}{V},
$$

where $P$ is the detonation pressure $(\mathrm{Pa}), A$ and $B$ are the explosive parameters $(\mathrm{Pa}), R_{1}, R_{2}$, and $\omega$ are the explosive characteristic parameters (dimensionless), $E_{0}$ is the internal energy of the detonation product $\left(\mathrm{J} \cdot \mathrm{m}^{-3}\right)$, and $\mathrm{V}$ is initial relative volume (dimensionless). The explosive parameter settings are listed in Table 2.

3.3. Material Model of Slit Pipe. A stainless steel pipe is used for the slitting pipe, which is described by the Johnson-Cook constitutive model [25]. The Johnson-Cook constitutive model is often used to describe the large deformation, high strain rate, and high-temperature process of materials. Its yield stress expression is

$$
\gamma=\left(a+b \varepsilon_{P}^{n}\right)\left(1+c \ln \dot{\varepsilon}_{P}^{* *}\right)\left(1-T_{H}^{m}\right),
$$

where $\varepsilon_{\mathrm{p}}$ is the equivalent plastic strain (dimensionless), $\varepsilon_{p}^{*}$ is the normalized plastic strain rate (dimensionless), $a$ is the quasi-static yield stress $(\mathrm{Pa}), b$ is the strain hardening 
TABLE 1: Parameters of rock material.

\begin{tabular}{lccccccc}
\hline$\rho\left(\mathrm{kg} \cdot \mathrm{m}^{-3}\right)$ & $G(\mathrm{~Pa})$ & $f_{\mathrm{c}}(\mathrm{Pa})$ & $f_{\mathrm{t}}^{*}$ & $f_{\mathrm{s}}^{*}$ & $g_{\mathrm{c}}^{*}$ & $g_{\mathrm{t}}^{*}$ & $Q_{0}$ \\
\hline 2750 & $1.67 \times 10^{10}$ & $3.5 \times 10^{7}$ & 0.1 & 0.18 & 0.53 & 0.7 & 0.6805 \\
$\mathrm{~B}$ & $\mathrm{~A}$ & $\mathrm{~N}$ & $\beta_{\mathrm{c}}$ & $\beta_{\mathrm{t}}$ & $D_{1}$ & $D_{2}$ & $\varepsilon_{\mathrm{f}_{\min }}$ \\
0.0105 & 1.60 & 0.61 & 0.032 & 0.036 & 0.04 & 1 & 0.01 \\
\hline
\end{tabular}

Note. $\rho$ is the mass density. $G$ is the shear modulus. $f_{\mathrm{t}}^{*}$ is the relative tensile strength. $f_{\mathrm{s}}^{*}$ is the relative shear strength. $g_{\mathrm{c}}^{*}$ is the compressive yield surface parameter. $g_{\mathrm{t}}^{*}$ is the tensile yield surface parameter. $Q_{0}$ is the meridian ratio of tension and compression. $\mathrm{B}$ is the brittle to ductile transition. $\beta_{\mathrm{c}}$ is the compressive strain rate dependence exponent. $\beta_{\mathrm{t}}$ is the tensile strain rate dependence exponent.

TABLE 2: Explosive materials and state equation parameters.

\begin{tabular}{lccccccc}
\hline $\begin{array}{l}\rho \\
\left(\mathrm{kg} \cdot \mathrm{m}^{-3}\right)\end{array}$ & $\begin{array}{c}D \\
\left(\mathrm{~m} \cdot \mathrm{s}^{-1}\right)\end{array}$ & $A(\mathrm{~Pa})$ & $B(\mathrm{~Pa})$ & $R_{1}$ & $R_{2}$ & $\omega$ & $\begin{array}{c}E_{0} \\
\left(\mathrm{~J} \cdot \mathrm{m}^{-3}\right)\end{array}$ \\
\hline 1200 & 3200 & $3.73 \times 10^{11}$ & $3.74 \times 10^{9}$ & 4.15 & 0.9 & 0.35 & $6 \times 10^{9}$ \\
\hline
\end{tabular}

Note. $\rho$ is the material density. $D$ is the detonation velocity.

coefficient $(\mathrm{Pa}), c, n$, and $m$ are material constant (dimensionless), and $T_{\mathrm{H}}$ is the relative melting temperature (K). The material parameters of the slit pipe are listed in Table 3.

3.4. Ground Stress Loading Scheme. We consider two different cases of ground stress, two-way equal pressure and two-way different pressures. In studying the influence of bidirectional isostatic ground stress on the blasting effect, the same ground stresses were used for $\sigma_{x}$ and $\sigma_{y}$, which were 10 , $20,30,40$, and $50 \mathrm{MPa}$. In studying the influence of two-way different pressure in situ stress on the blasting, $\sigma_{\mathrm{x}}=40 \mathrm{MPa}$ and $\sigma_{y}$ is $10,20,30,50,60$, and $70 \mathrm{MPa}$.

\section{Analysis of Two-Way Equal Pressure Results}

4.1. Crack Analysis. Figure 4 shows the double-hole blasting effect of the slit cartridge under different ground stresses. When no ground stress is applied, the cracks between the two blasting holes in the cutting direction completely penetrate and form multiple cracks and the development of cracks in the cutting direction is better than that in the noncutting direction. As the ground stress increases, the restraining effect of the ground stress on blasting cracking gradually becomes evident, and the number of cracks between the two blast holes gradually decreases. When $\sigma_{x}=\sigma_{y}=30 \mathrm{MPa}$, the cracks between the two blasting holes cannot penetrate. As the ground stress increases further, the blasting fracture range decreases. When $\sigma_{x}=\sigma_{y}=50 \mathrm{MPa}$, cracks do not longer occur between the two blast holes and the rock mass is damaged only near the blast hole. At this time, the kerf and nonkerf directions of the crack development are roughly the same. When the ground stress is small, the horizontal crack propagation between the two holes is better than those in the $45^{\circ}$ direction and vertical direction owing to the directional energy gathering effect of the slit charge, which leads to a stress wave after an explosion in the horizontal direction considerably larger than that in the vertical direction. As a result, the ground stress cannot be effectively suppressed; thus, the cracks shift toward the horizontal end. When the ground stress is large, the ground stress inhibits crack development and the crack propagation in the $45^{\circ}$ direction is best. The crack development in the area close to $45^{\circ}$ is better than that in the area far away from $45^{\circ}$.

4.2. Stress Analysis. To study the influence of the ground stress on the blasting stress wave, some measuring points are selected to draw the stress-time curve, as shown in Figure 5. Because this study mainly considers the stress law in the direction of the slit between two blast holes, four units with distances of $5,10,15$, and $20 \mathrm{~cm}$ from the center of the left blast hole in the horizontal direction are selected as research objects. Figures 5(e)-5(h) show partially enlarged views of the stress peak. Before initiation, the six groups of models exhibit stable curves according to their respective set ground stress values, which indicates that the ground stress is loaded. In the boosting stage after the start of blasting, at $d=5 \mathrm{~cm}$, the peak value of the stress wave decreases with the increase in ground stress and the rate of pressure increase decreases with the increase in ground stress. On the contrary, when $d=10,15$, and $20 \mathrm{~cm}$, the peak value of the stress wave and pressure increase rate increase with the increase in ground stress. This is in good agreement with the theoretical analysis results presented in the first chapter. In the pressure relief stage after the blasting, a higher initial ground stress leads to a higher stress that remained after the completion of the unloading. This shows that the initial ground stress is an important factor that affects the stress state of the rock mass after the blasting.

4.3. Stress Peak Analysis. We present the change curves of the peak stress with the distance under different in situ stress conditions in Figure 6. A higher ground stress leads to a slower attenuation of the stress wave at a distance from the blast hole. The opposite pattern appears at a distance. This is a good verification of the theoretical results of the first chapter.

\section{Analysis of Two-Way Different Pressure Results}

5.1. Crack Analysis. When the horizontal ground stress is the same, the double-hole blasting effect of the slit charge under different vertical ground stresses is shown in Figure 7. As the vertical ground stress increases, the crack development effect between the two holes in the cutting direction gradually becomes worse and the crack cannot be penetrated. When the vertical ground stress increases to a certain value, cracks in the horizontal area almost do not develop, because the in situ stress has a significant inhibitory effect on the development of cracks in the vertical direction. In addition, the comparison of ( $\left.\sigma_{x}=40 \mathrm{MPa}, \sigma_{y}=10 \mathrm{MPa}\right)$ and $\left(\sigma_{x}=10 \mathrm{MPa}\right.$, $\left.\sigma_{y}=10 \mathrm{MPa}\right)$ shows that $\left(\sigma_{x}=40 \mathrm{MPa}, \sigma_{y}=10 \mathrm{MPa}\right)$ produces more cracks in the cutting direction. The crack development effect is significantly better than $\left(\sigma_{x}=10 \mathrm{MPa}\right.$, $\left.\sigma_{y}=10 \mathrm{MPa}\right)$. The comparison shows that $\left(\sigma_{x}=40 \mathrm{MPa}\right.$, $\left.\sigma_{y}=70 \mathrm{MPa}\right)$ produces fewer cracks in the horizontal 
TABLE 3: The parameters of the slit pipe material.

\begin{tabular}{lcccccccc}
\hline$\rho\left(\mathrm{kg} \cdot \mathrm{m}^{-3}\right)$ & $G(\mathrm{~Pa})$ & $a(\mathrm{~Pa})$ & $b(\mathrm{~Pa})$ & $c$ & $n$ & $m$ & $T_{\mathrm{H}}(\mathrm{K})$ & $\gamma$ \\
\hline 7896 & $8.18 \times 10^{10}$ & $3.5 \times 10^{8}$ & $2.75 \times 10^{8}$ & 0.022 & 0.36 & 1 & 1811 & 2.17 \\
\hline
\end{tabular}

Note. $\rho$ is the material density. $G$ is the shear modulus. $\gamma$ is the Gruneisen coefficient.

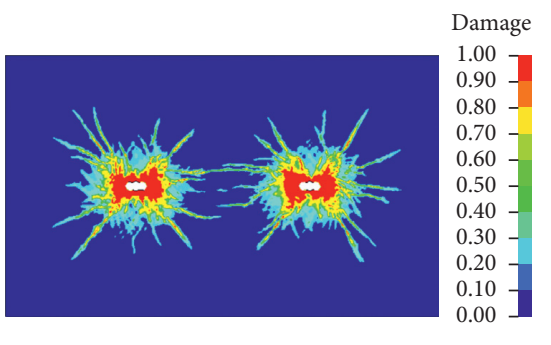

(a)

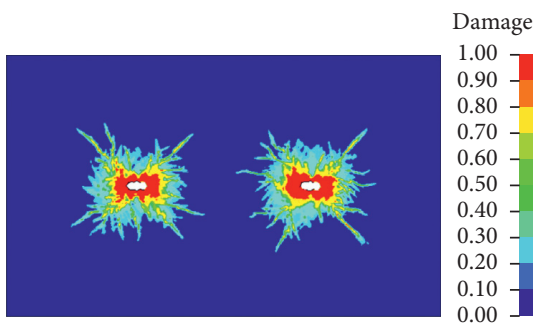

(d)

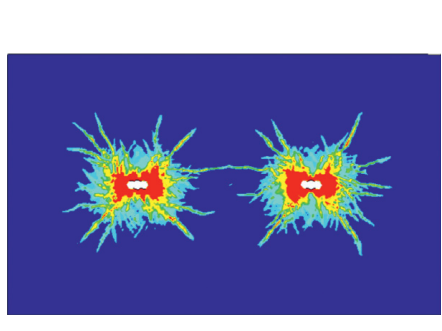

(b)

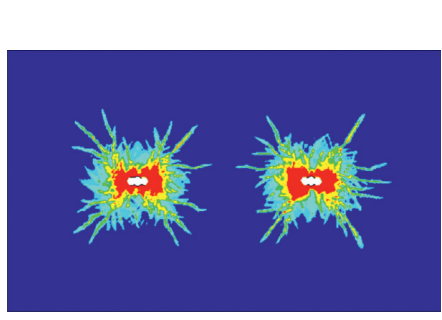

(e)

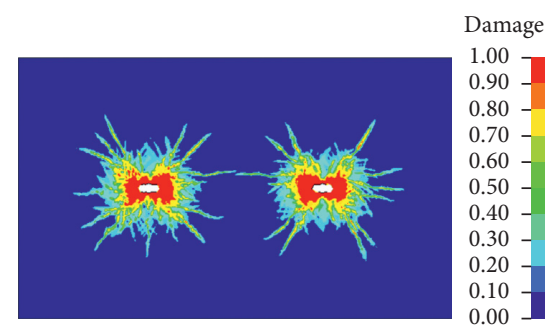

(c)

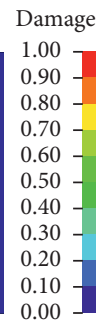

$0.00]$

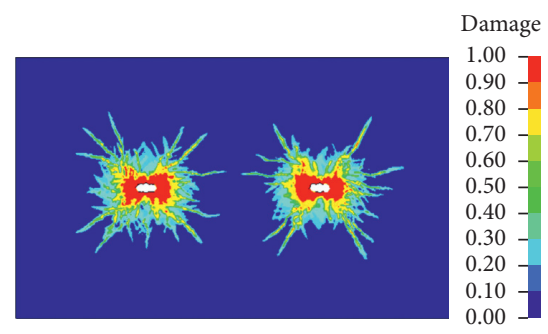

(f)

Figure 4: Effect of double-hole blasting of cutting seam charge under different ground stress. (a) $\sigma_{x}=\sigma_{y}=0 \mathrm{MPa}$. (b) $\sigma_{x}=\sigma_{y}=10 \mathrm{MPa}$. (c) $\sigma_{x}=\sigma_{y}=20 \mathrm{MPa}$. (d) $\sigma_{x}=\sigma_{y}=30 . \mathrm{MPa}$. (e) $\sigma_{x}=\sigma_{y}=40 \mathrm{MPa}$. (f) $\sigma_{x}=\sigma_{y}=50 \mathrm{MPa}$.

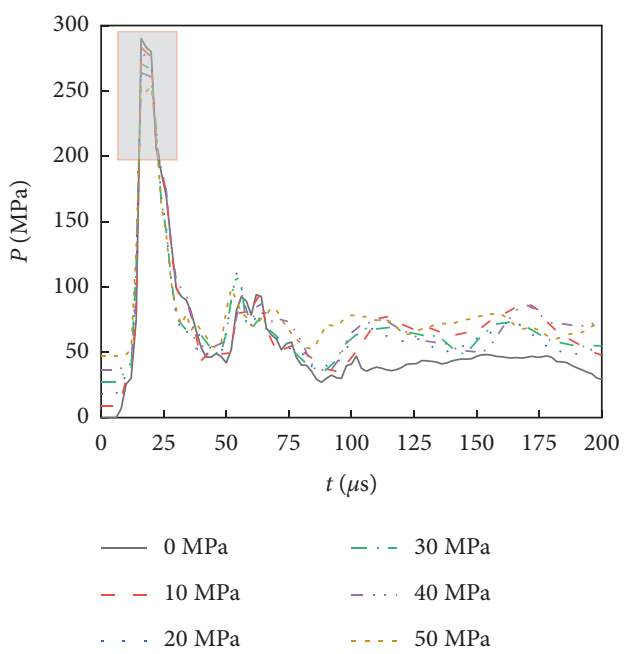

(a)

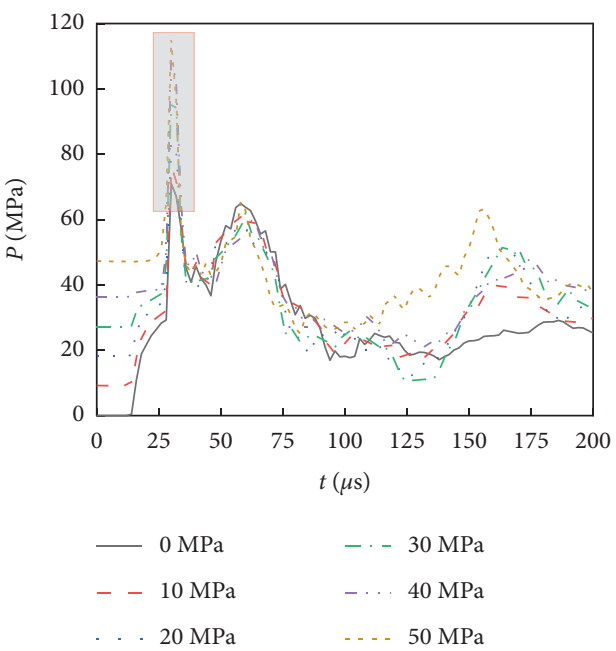

(b)

FIgURE 5: Continued. 

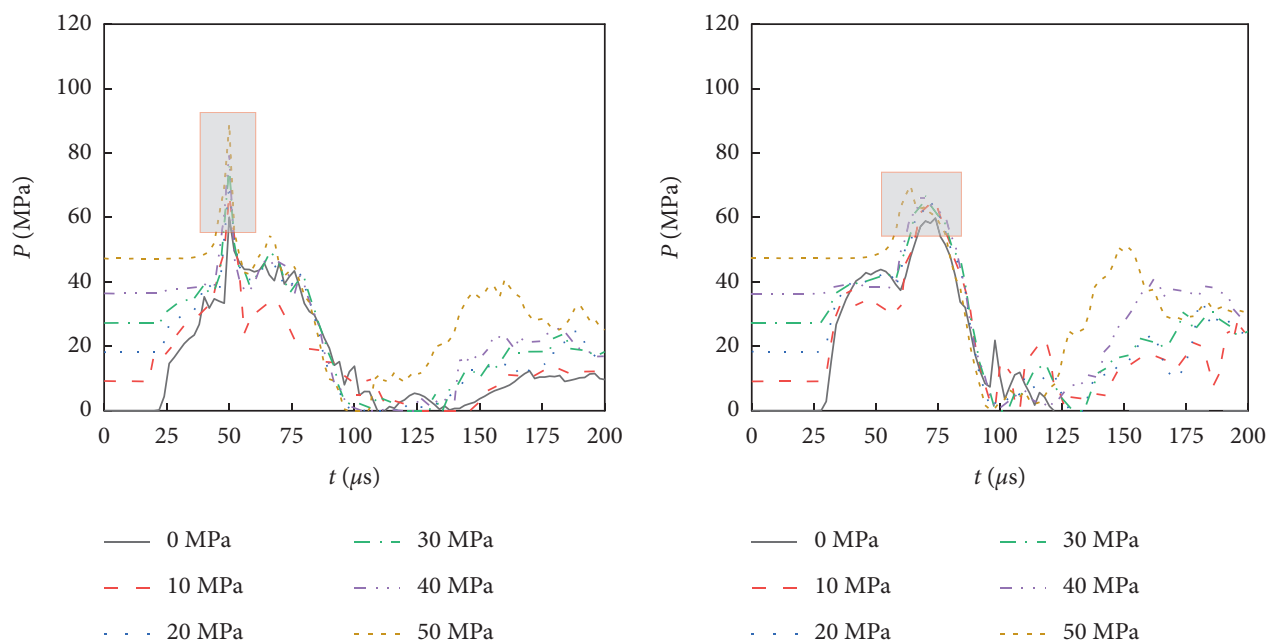

(c)

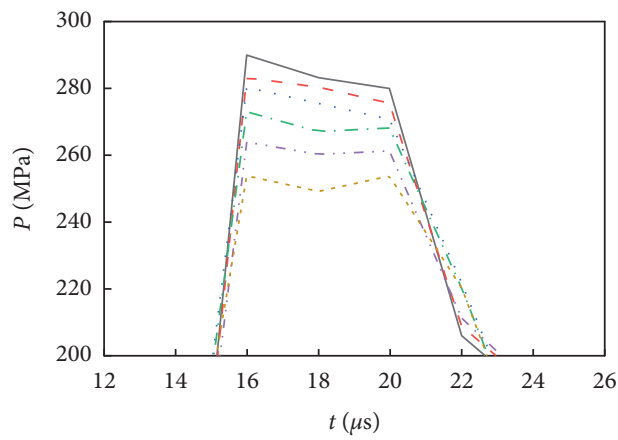

(d)
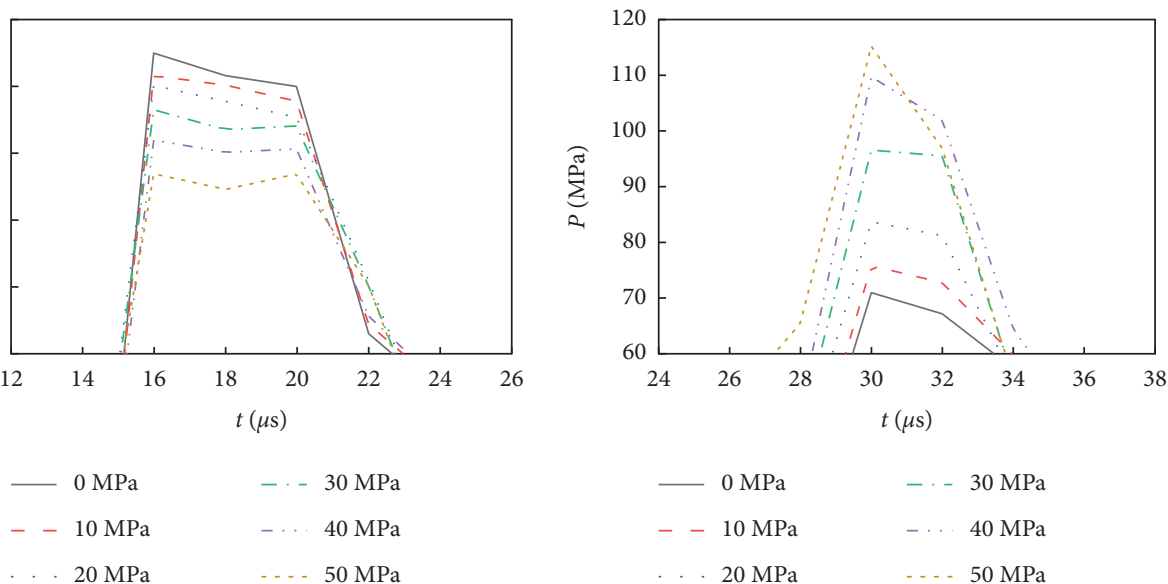

(e)

(f)
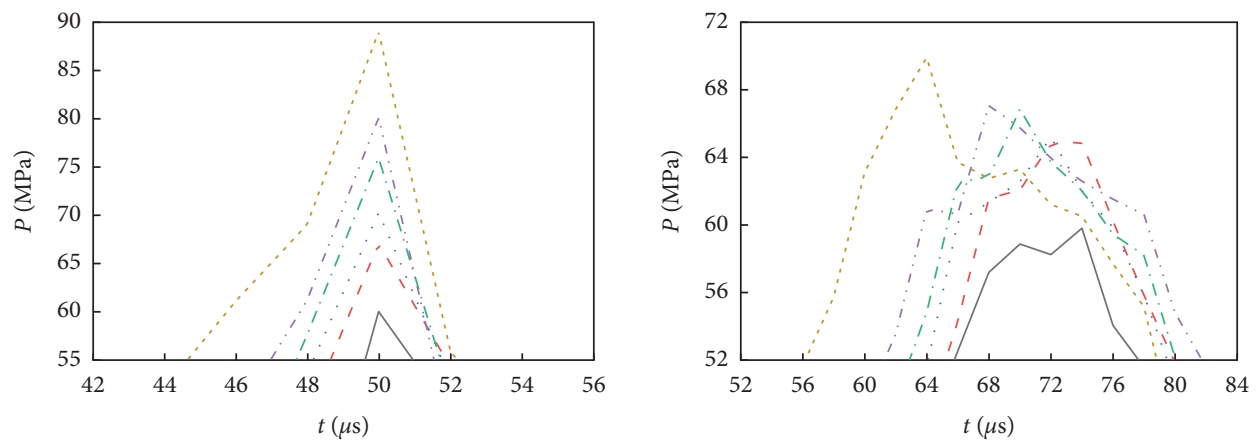

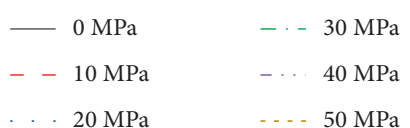

(g)

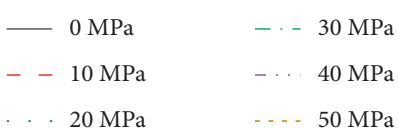

(h)

FIGURE 5: Stress-time curves of measuring points at different distances under two-way equal pressure. (a) $d=5 \mathrm{~cm}$. (b) $d=10 \mathrm{~cm}$. (c) $d=15 \mathrm{~cm}$. (d) $d=20 \mathrm{~cm}$. (e) $d=5 \mathrm{~cm}$. (f) $d=10 \mathrm{~cm}$. (g) $d=5 \mathrm{~cm}$. (h) $d=10 \mathrm{~cm}$. 


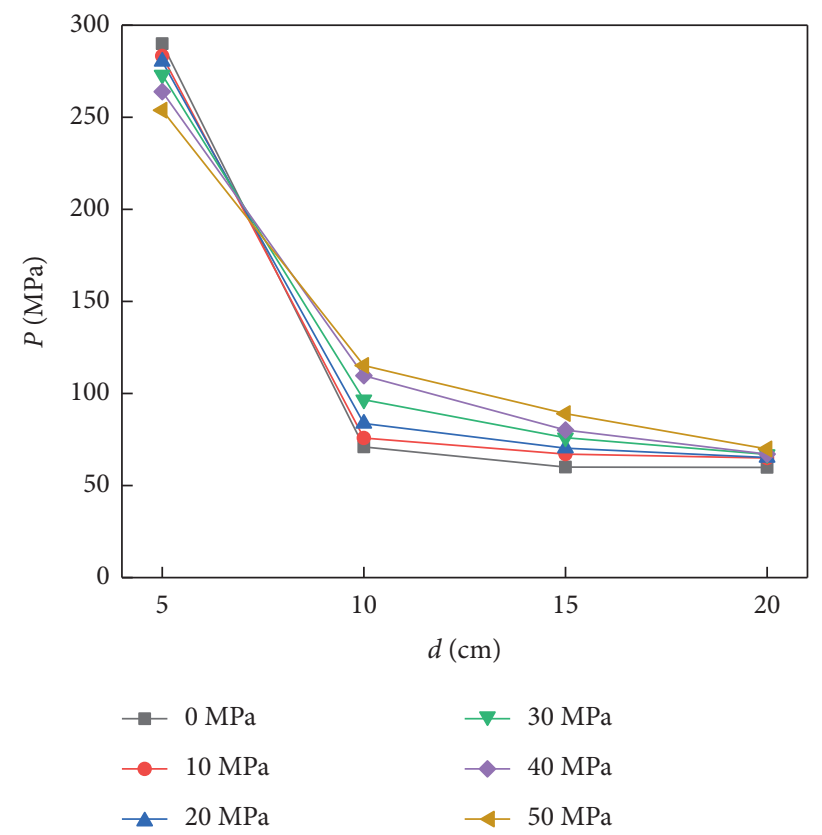

FIgURE 6: Change curve of stress peak value with distance.

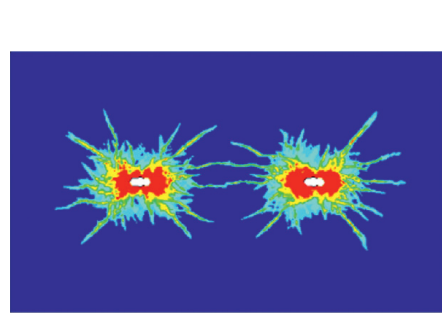

(a)

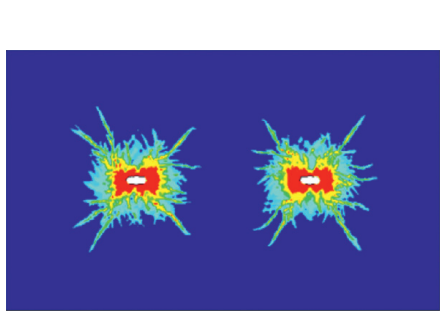

(d)

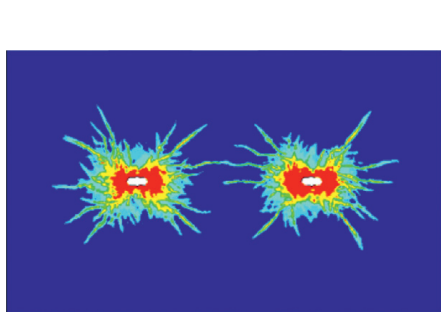

(b)
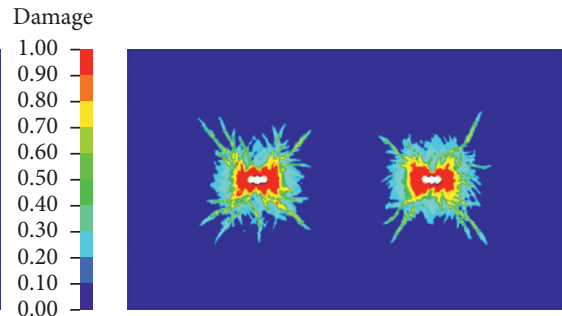

(e)
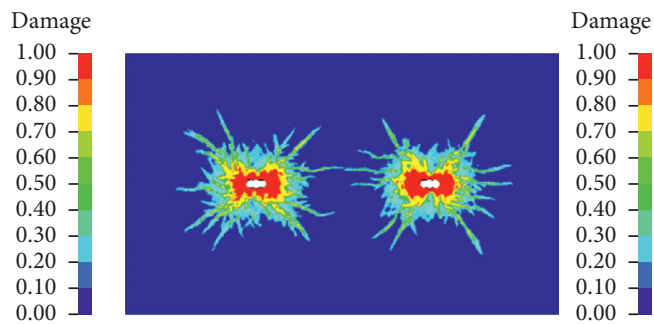

(c)
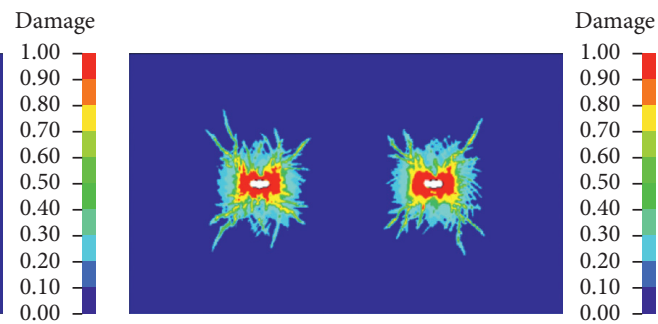

(f)

Figure 7: The effect of double-hole blasting of cutting seam charge under different vertical ground stresses. (a) $\sigma_{y}=10 \mathrm{MPa}$. (b) $\sigma_{y}=20 \mathrm{MPa}$. (c) $\sigma_{y}=30 \mathrm{MPa}$. (d) $\sigma_{y}=50 . \mathrm{MPa}$. (e) $\sigma_{y}=60 \mathrm{MPa}$. (f) $\sigma_{y}=70 \mathrm{MPa}$

direction than $\left(\sigma_{x}=40 \mathrm{MPa}, \sigma_{y}=40 \mathrm{MPa}\right)$, but more cracks develop in the vertical direction. This is manifested in the blasting process as cracks are more likely to develop toward high stress areas.

5.2. Stress Analysis. Similarly, four units with a distance of 5 , 10,15 , and $20 \mathrm{~cm}$ from the center of the left blast hole in the horizontal direction are selected as research objects. To facilitate the study on the loading amplitude of the blasting stress wave, the ground stress is used as the reference point and the curve of the simulation is shifted to the same horizontal point, as shown in Figure 8. Figures $8(\mathrm{e})-8(\mathrm{~h})$ show partially enlarged views of the relative stress peak. At $d=5 \mathrm{~cm}$ and $d=10 \mathrm{~cm}$, the loading amplitude of the stress wave after initiation gradually increases at $\sigma_{y}=10,20$, and $30 \mathrm{MPa}$. When $\sigma_{y}=50,60,70 \mathrm{MPa}$, it gradually decreases. At $d=15 \mathrm{~cm}$ and $d=20 \mathrm{~cm}$, a higher vertical ground stress leads to a smaller relative load amplitude after blasting. When the horizontal ground stress is the same, a smaller vertical 

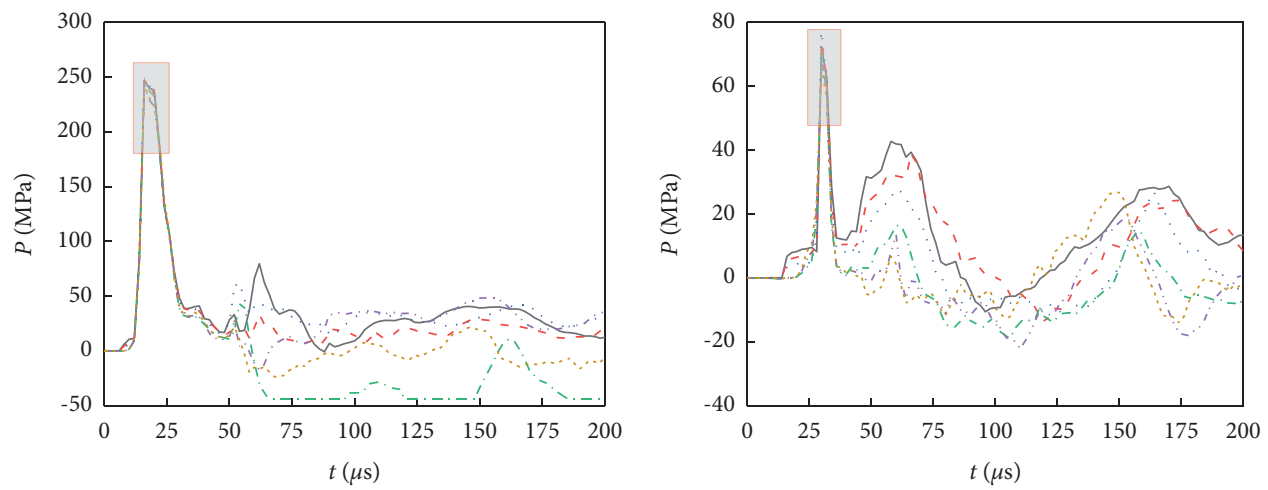

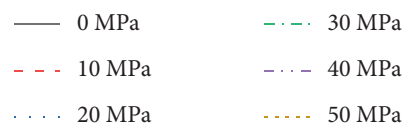

(a)

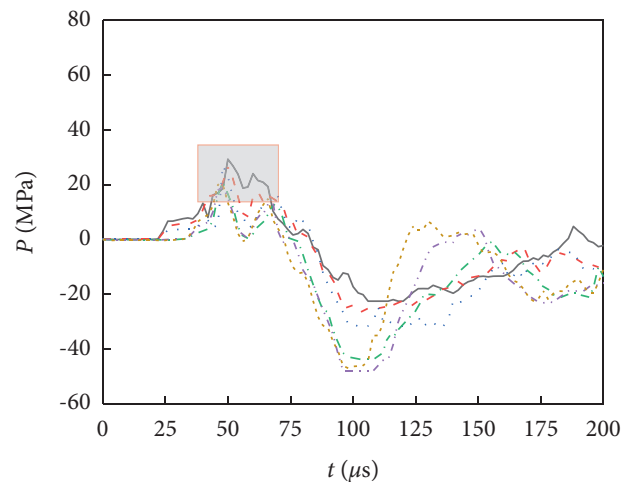

$-0 \mathrm{MPa}$

- . $10 \mathrm{MPa}$

$20 \mathrm{MPa}$

(c)

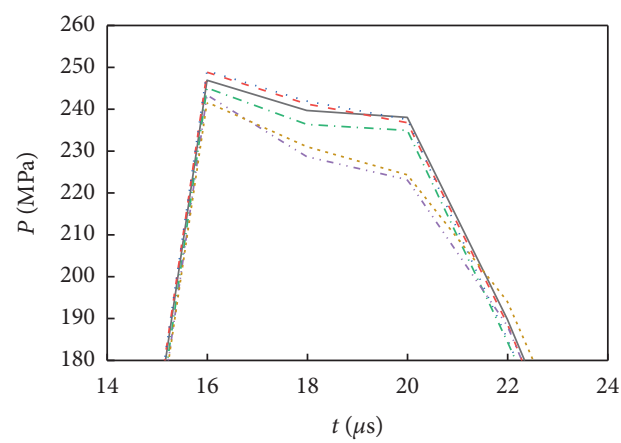

$-\quad 0 \mathrm{MPa}$

- . $10 \mathrm{MPa}$

$20 \mathrm{MPa}$

(b)
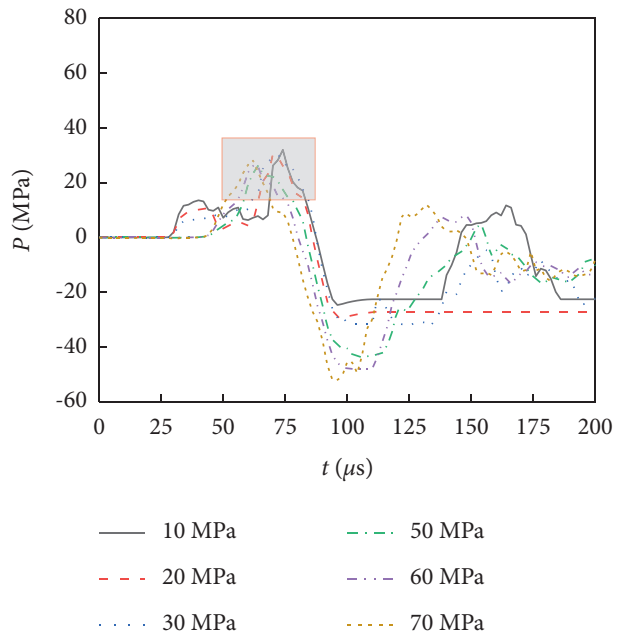

(d)

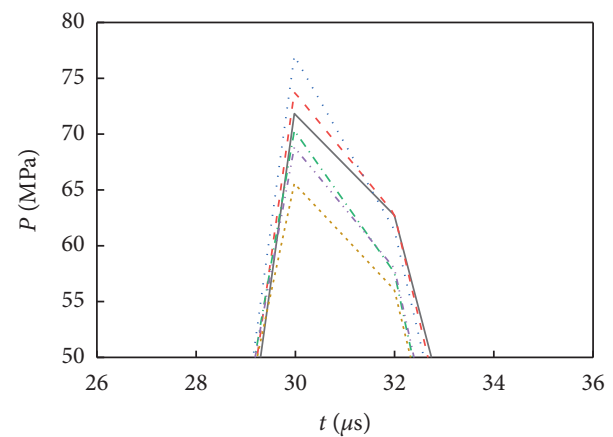

$-0 \mathrm{MPa}$
$\ldots-10 \mathrm{MPa}$

-. - $30 \mathrm{MPa}$

$-0 \mathrm{MPa}$

-. - $30 \mathrm{MPa}$

-.. $40 \mathrm{MPa}$

.... $50 \mathrm{MPa}$

(e) (f)

FIgURE 8: Continued. 


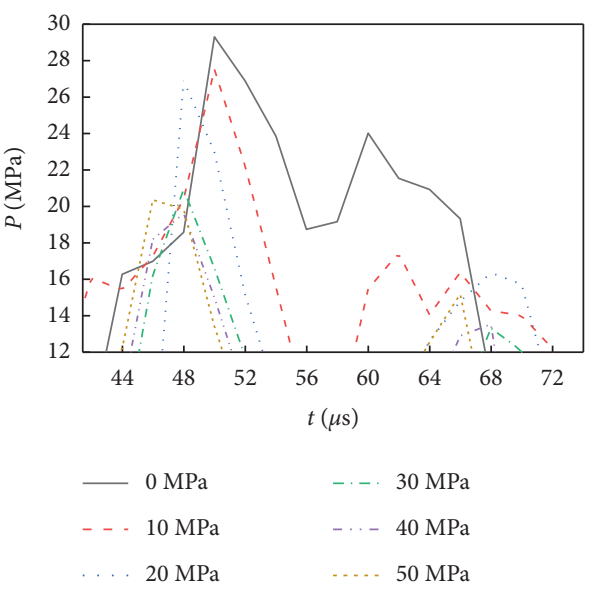

(g)

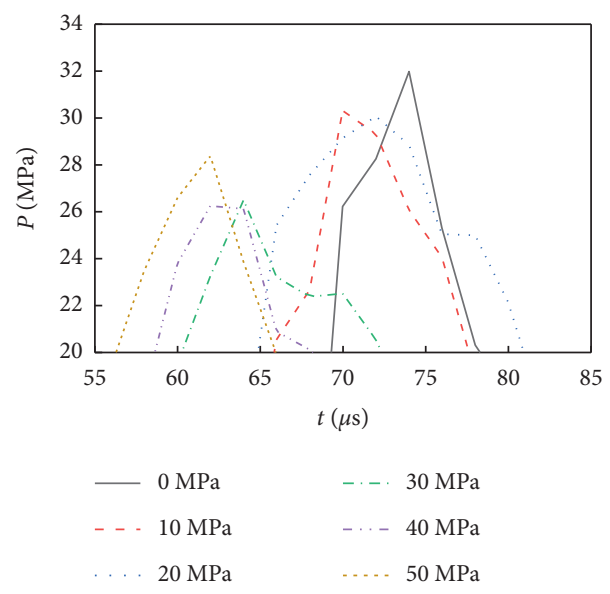

(h)

Figure 8: Stress-time curve of measuring points at different distances under two-way different pressure. (a) $d=5 \mathrm{~cm}$. (b) $d=10 \mathrm{~cm}$. (c) $d=15 \mathrm{~cm}$. (d) $d=20 \mathrm{~cm}$. (e) $d=5 \mathrm{~cm}$. (f) $d=10 \mathrm{~cm}$. (g) $d=5 \mathrm{~cm}$. (h) $d=10 \mathrm{~cm}$.

ground stress leads to more easily distributed energy after blasting in the horizontal vicinity, thus promoting crack propagation in the horizontal vicinity. In the horizontal far zone, the attenuation of the blasting stress wave is slower when the ground stress is smaller and the propagation distance is longer, which promotes development of remote cracks.

\section{Conclusion}

Two theoretical models were developed to analyze the stress wave propagation and crack propagation of rock mass blasting under in situ stress conditions. When the rock mass was close to the blasting source, the loading stress did not increase sufficiently upon unloading, and the peak value of the stress wave decreased with the increase in ground stress. The opposite behavior was obtained at the end of the rock mass, away from the blasting source. Under the condition of two-way isostatic pressure, the cracks developed at $45^{\circ}$ away from the principal stress direction; closer to the $45^{\circ}$ direction, the cracks were denser. The $45^{\circ}$-direction cracks were longest. Under the condition of two-way different pressures, the crack developed in the direction of $\theta\left(\theta=\arctan \left(\sigma_{x} / \sigma_{y}\right)\right)$ with the principal stress angle.

The two-way equal pressure simulation revealed that a higher ground stress led to a large suppression of the blasting effect. When the ground stress was small, the cutting medicine package could not be effectively inhibited. The crack was skewed in the tangential direction and penetrated between the two holes. When the ground stress was large, the crack preferentially developed in the $45^{\circ}$ direction. Near the blast hole, a higher ground stress led to a slower attenuation of the stress wave. The opposite pattern appeared at a distance.

The two-way different pressure simulations showed that the ground stress had a significant inhibitory effect on the development of vertical cracks. The cracks were more likely to develop in the direction of high stress after blasting. The stress analysis of the measuring points showed that when the vertical ground stress was unchanged, a smaller horizontal ground stress led to more easily distributed energy in the horizontal vicinity of the blasting source after blasting, thereby promoting crack propagation. The attenuation of the stress wave in the far area was slower, and thus the stress wave could more easily propagate farther, thereby increasing the crack development length.

\section{Data Availability}

The numerical simulation data used to support the findings of this study are included within the article.

\section{Conflicts of Interest}

The authors declare that they have no conflicts of interest.

\section{Authors' Contributions}

J.Y. Zhang and Z.G. Liu conceptualized the study and reviewed and edited the manuscript and were responsible for methodology; J.Y. Zhang was responsible for software; G.D. Qiao and S.G. Fu validated the data; J.Y. Zhang performed formal analysis, investigated the data, curated the data, prepared the original draft, and visualized the study and was responsible for project administration; Z.G. Liu was responsible for resources, study supervision, and funding acquisition. All authors have read and agreed to the published version of the manuscript.

\section{Acknowledgments}

This research was funded by the National Science Foundation of China (Grant no. 52074013). 


\section{References}

[1] H. P. Xie, "Research framework and anticipated results of deep rock mechanics and mining theory," Chinese Journal of Chemical Engineering, vol. 49, no. 2, pp. 1-16, 2017.

[2] M. C. He, H. P. Xie, S. P. Peng, and Y. D. Jiang, "Study on rock mechanics in deep mining engineering," Chinese Journal of Rock Mechanics and Engineering, vol. 16, pp. 2803-2813, 2005.

[3] H. P. Xie, "Research review of the state key research development program of China: deep rock mechanics and mining theory," Journal of China Coal Society, vol. 44, no. 5, pp. 1283-1305, 2019.

[4] Q. Zong and Q. F. Ren, "Experimental research on mid-deep hole blasting technology in diphead tunnel of coal mine hard rock," Chinese Journal of Blasting, vol. 28, no. 2, pp. 49-52, 2011.

[5] G. W. Ma and X. M. An, "Numerical simulation of blastingind9uuced rock fractures," International Journal of Rock Mechanics and Mining Sciences, vol. 45, no. 6, pp. 966-975, 2008.

[6] J. H. Yang, C. Yao, Q. H. Jiang, W. B. Lu, and S. H. Jiang, "2D numerical analysis of rock damage induced by dynamic insitu stress redistribution and blast loading in underground blasting excavation," Tunnelling and Underground Space Technology, vol. 70, pp. 221-232, 2017.

[7] S. Y. Xiao, Y. J. Jiang, Z. X. Liu, and L. J. Su, "Hard rock blasting energy distribution and fragmentation characteristics under high earth stress," Chinese Journal of Vibration and Shock, vol. 37, no. 15, pp. 143-149, 2018.

[8] C. Yi, D. Johansson, and J. Greberg, "Effects of in-situ stresses on the fracturing of rock by blasting," Computers and Geotechnics, vol. 104, pp. 321-330, 2018.

[9] J. J. Ge, Experimental Study on Crack Propagation of Rock Blasting under Initial Stress State, Anhui University of Science and Technology, Huainan, China, 2020.

[10] J. H. Yang, W. B. Sun, C. Yao, and X. B. Zhang, "Mechanism of rock fragmentation by multi-hole blasting in highlystressed rock masses," Chinese Journal of Explosion and Shock Waves, vol. 40, no. 07, pp. 118-127, 2020.

[11] Q. W. Li and B. Xiang, "Rockburst prediction on the superimposed effect of excavation accumulation energy and blasting vibration energy in deep roadway," Journal Shock and Vibration, vol. 2021, 2021.

[12] L. X. Xie, W. B. Lu, Q. B. Zhang, Q. H. Jiang, M. Chen, and J. Zhao, "Analysis of damage mechanisms and optimization of cut blasting design under high in-situ stresses," Tunnelling and Underground Space Technology, vol. 66, pp. 19-33, 2017.

[13] X. Liu, P. Yan, W. B. Lu et al., "Effects of the high in-situ stress level on the acoustic detection and the damage degree dvaluation ofthe excavation damage zone," Advanced Engineering Sciences, vol. 51, 2019.

[14] Y. Fan, X. Z. Cui, Z. D. Leng, Y. R. Zhou, J. W. Zheng, and F. Wang, "Development of a model to predict vibrations induced by blasting excavation of deep rock masses under high in situ stress," J.Shock and Vibration, vol. 2020, 2020.

[15] F. P. Zhang, Q. Q. Hao, X. L. Wang, and Z. G. Qiu, "Design method for specific charge in deep mining considering influence of in situ stress," Shock and Vibration, vol. 2021, 2021.

[16] L. L Wang, The Basis of Stress Wave, pp. 80-86, National Defense Industrial Press, Beijing, China, 2005.

[17] X. P. Li, K. W. Song, Y. Luo, J. H. Huang, J. X. Zhou, and W. H. Dun, "Study on influence of high in-situ stress on cut blasting and blast waves," Chinese Journal of Blasting.vol. 36, no. 2, pp. 13-18+53, 2019.
[18] F. H. Zhu, ZG. Liu, K. Gao, and J. Liu, "Tests for damage and failure characteristics of coal thickness variation area under blasting load," Chinese Journal of Vibration and Shock, vol. 38, no. 3, pp. 141-148, 2019.

[19] D. Y. Guo, S. J. Zhao, T. G. Zhu, and C. Zhang, "Crack propagation and coalescence mechanism of double-hole cumulative blasting in coal seam," Chinese Journal of Engineering, vol. 42, no. 12, pp. 1613-1623, 2020.

[20] B. Cheng, H. B. Wang, and Q. Zong, "Numerical simulation on blasting mechanism of slotted cartridge based on coupled SPH-FEM algorithm," Chinese Journal of Energetic Materials, vol. 28, no. 04, pp. 300-307, 2020.

[21] W. Riedel, K. Thoma, S. Hiermaier, and E. Schmolinske, "Penetrating of reinforced concrete by BETA-B-500 numerical analysis using a new macroscopic concrete model for hydrocodes," in Proceedings of the ninth international symposium of IEMS, pp. 315-322, Berlin, Germany, June 1999.

[22] H. Wang, Z. Wang, J. Wang et al., "Effect of confining pressure on damage accumulation of rock under repeated blast loading," International Journal of Impact Engineering, vol. 156, p. 103961, 2021.

[23] K. Liu, Q. Li, C. Wu, X. Li, and J. Li, "A study of cut blasting for one-step raise excavation based on numerical simulation and field blast tests," International Journal of Rock Mechanics and Mining Sciences, vol. 109, no. 6, pp. 91-104, 2018.

[24] K. Gao, P. Huang, Z.-G. Liu, J. Liu, F. Wang, and C.-M. Shu, "Pressure relief by blasting roof cutting in close seam group mining under thick sandstone to enhance gas extraction for mining safety," Processes, vol. 9, no. 4, p. 603, 2021.

[25] S. C. Qian, Q. Gan, Z. W. Ren, N. S. Cheng, and C. G. Feng, "Numerical simulation of the factors affecting the ignition threshold of an exploding foil initiator," Chinese Journal of Energetic Materials, vol. 26, no. 03, pp. 248-254, 2018. 